\title{
The endogenous cannabinoid, anandamide, induces COX-2- dependent cell death in apoptosis-resistant colon cancer cells
}

\author{
HELENA A. PATSOS ${ }^{1}$, ALEXANDER GREENHOUGH ${ }^{1}$, DIANE J. HICKS ${ }^{1}$, MANAL AL KHARUSI ${ }^{1}$, \\ TRACEY J. COLLARD ${ }^{1}$, JON D. LANE ${ }^{2}$, CHRISTOS PARASKEVA ${ }^{1}$ and ANN C. WILLIAMS ${ }^{1}$ \\ ${ }^{1}$ Cancer Research UK Colorectal Tumour Biology Group, Department of Cellular and Molecular Medicine and \\ ${ }^{2}$ Department of Biochemistry, School of Medical Sciences, University Walk, University of Bristol, BS8 1TD, UK
}

Received January 15, 2010; Accepted March 2, 2010

DOI: 10.3892/ijo_00000666

\begin{abstract}
Despite recent advances in understanding colorectal tumour biology, there is still a need to improve the 5-year survival rate of patients with colorectal cancer as approximately $40 \%$ of patients presenting with advanced disease will remain resistant to therapy. One of the major contributing factors in resistance to therapy is the failure of colorectal tumour cells to undergo apoptosis. Hence there is an urgent need to develop novel therapeutic approaches that can target apoptosis-resistant cells. To this end, we investigated the potential efficacy of the endogenous cannabinoid anandamide to induce cell death in apoptosis-resistant colon cancer cells. Here, for the first time, we show that anandamide can induce cell death in the apoptosis-resistant HCT116 $\mathrm{Bax}^{-/-}$ colorectal cell line. Importantly, we provide direct genetic evidence that this induction of cell death is dependent on COX-2 expression. Interestingly, increased COX-2 expression also sensitised the SW480 colorectal cancer cell line (low endogenous COX-2) to anandamide-induced death, whereas COX-2 suppression by RNAi inhibited anandamide-induced cell death in the HCA7 colorectal cancer cell line (high endogenous COX-2 expression). This COX-2-dependent death was independent of cannabinoid receptor engagement (CB1 or $\mathrm{CB} 2$ ), and not a direct consequence of reactive oxygen species (ROS) formation. This study demonstrates a novel utilisation for COX-2 expression, targeting apoptotic defective colorectal cancer cells for destruction by anandamide. As COX-2 is not expressed in the normal colorectal epithelium, but highly expressed in colorectal tumours and apoptosis resistance contributes to treatment failure, these data suggest that anandamide has the potential to be an effective therapeutic in colorectal cancer.
\end{abstract}

Correspondence to: Professor C. Paraskeva, Cancer Research UK Colorectal Tumour Biology Group, Department of Cellular and Molecular Medicine, School of Medical Sciences, University Walk, University of Bristol, BS8 1TD, UK

E-mail: c.paraskeva@bristol.ac.uk

Key words: cannabinoid, arachidonoylethanolamide (anandamide, AEA), colorectal carcinoma, cyclooxygenase-2, non-apoptotic cell death

\section{Introduction}

Colorectal cancer remains the second highest cause of cancer death in the UK and despite recent progress, approximately $40 \%$ of patients with advanced disease will be resistant to current therapies. One of the reasons for the refractory nature of colorectal tumours to treatment arises from their innate ability to evade apoptosis (one of the hallmarks of cancer described by Hanahan and Weinberg) (1). Several mechanisms exist by which tumour cells can suppress apoptosis, including Bax mutations, p53 loss, hyperactive survival signalling or up-regulation of anti-apoptotic $\mathrm{Bcl}-2 / \mathrm{Bcl}-\mathrm{x}_{\mathrm{L}}$ proteins (2-4). Therefore the search for new effective therapies is a critical area of research.

In recent years cannabinoids have become increasingly attractive compounds for chemotherapy because they have been shown to have anti-proliferative and cytotoxic properties in many tumour types (reviewed in refs. 5-7). Cannabinoids, both plant-derived and endogenous, are characterised by their ability to activate cannabinoid receptors $(8,9)$. Cannabinoid receptors, CB1 and CB2, are G-protein-coupled cell surface receptors classically coupled to the adenylyl cyclase and the cAMP-protein kinase A (PKA) pathway(s) $(10,11)$ and to the MAPK and PI3K pathways $(5,12)$. We have recently shown that activation of the $\mathrm{CB} 1$ receptor by the plant-derived cannabinoid, $\Delta^{9}$-tetrahydrocannabinol (THC) induces CB1-dependent apoptosis via inhibition of both RAS-MAPK/ERK and PI3K-AKT signalling cascades in colon cancer cells, (two key survival pathways frequently deregulated in colorectal cancer (13). Furthermore, activation of CB1 was recently reported to attenuate intestinal tumour growth in $\mathrm{Apc}\left(\mathrm{Min} /{ }^{+}\right)$mice suggesting that the endogenous cannabinoid system may represent a potential therapeutic target for prevention or treatment of colorectal cancer (14).

The identification of cannabinoid receptors led to the hunt for endogenous ligands for CB1 and CB2. Several endogenous cannabinoid receptor ligands are now known to exist, termed endocannabinoids, the first discovered being $\mathrm{N}$ arachidonoyl ethanolamide (anandamide, AEA) (15). Endocannabinoids including anandamide and 2-arachidonoylglycerol play important roles in many biological processes including the reproductive system, cardiovascular system and the gastrointestinal tract (16). There is also accumulating 
evidence that endocannabinoids can modulate tumour cell fate-related decisions, such as cell growth, cell invasion and cell death (5). Anandamide and its analogue methanandamide have been reported to reduce cell growth $(17,18)$, inhibit cell migration (19) and invasion $(20,21)$, induce apoptosis (22) and induce cell death other than apoptosis $(23,24)$ in a number of different cancer cells. These effects can be either dependent $(17,19,20)$ or independent $(22,24,25)$ of $\mathrm{CB}$ receptors.

Further evidence for the antineoplastic effects of anandamide comes from in vivo studies involving the inhibition of anandamide degradation by a FAAH inhibitor, $\mathrm{N}$-arachidonoyl-serotonin; for example $\mathrm{N}$-arachidonoyl-serotonin increases available anandamide and results in reduced precancerous aberrant crypt foci formation in mouse colon (26). FAAH activity normally results in degradation of anandamide into arachidonic acid and ethanolamine ultimately producing prostaglandins via cyclooxygenase 2 (COX-2) (27). Alternatively anandamide itself can be metabolised by COX-2 into prostaglandin ethanolamides (PG-EAs) (28). Previously, we have reported that the ability of anandamide to induce cell death correlates with endogenous COX-2 levels and that pharmacological inhibition of COX-2 activity by selective NSAIDs can decrease the sensitivity of the colorectal cancer cells to anandamide (23). This led to the hypothesis that, as COX-2 is over-expressed in approximately $85 \%$ of colorectal tumour cells (29), high COX-2 expression could be targeted by anandamide to induce cell death in the cancer cells.

Here, we show that anandamide can induce cell death in the apoptosis-resistant colorectal cancer cells. Analysis of the anandamide-induced death in the HCT116 $\mathrm{Bax}^{-/-}$cell line $(30,31)$ revealed the induction of non-apoptotic cell death previously observed (23). Importantly, this cell death is dependent on the expression of COX-2 and not dependent on $\mathrm{CB}$ receptor engagement or ROS generation within the cells. As colorectal tumour cells that have acquired resistance to the induction of apoptosis are very difficult to treat using current therapies, the significance of this finding is that, by targeting tumour cells with high COX-2 expression to induce non-apoptotic cell death, anandamide represents a novel class of therapeutic agent that may kill tumour cells previously shown to be resistant to induction of cell death.

\section{Materials and methods}

Materials. SW480 and HT29 were obtained from the American Type Culture Collection. HCA7/C29 cells were a kind gift from Dr Susan Kirkland (Imperial College, London UK). HCT116 $\mathrm{Bax}^{+/-}$and HCT116 $\mathrm{Bax}^{-/-}$cells were a kind gift from Professor Bert Vogelstein (Johns Hopkins University, Baltimore, USA); these isogenic derivatives differ only in the presence or absence of the $B A X$ gene (31). SW480, HT29 and HCA7/C29 cell lines were maintained in DMEM containing $10 \%$ fetal bovine serum (FBS), glutamine $(2 \mathrm{mM})$, penicillin $(100 \mathrm{U} / \mathrm{ml})$ and streptomycin $(100 \mu \mathrm{g} / \mathrm{ml})$ at $37^{\circ} \mathrm{C}$ in an atmosphere containing 5\% $\mathrm{CO}_{2}$. $\mathrm{HCT} 116 \mathrm{Bax}^{+/-}$and HCT116 $\mathrm{Bax}^{--}$were maintained in McCoys $5 \mathrm{~A}$ medium supplemented with $10 \% \mathrm{FBS}$, glutamine $(2 \mathrm{mM})$, penicillin (100 U/ml) and streptomycin $(100 \mu \mathrm{g} / \mathrm{ml}) .2$-arachidonoy- lethanolamide (anandamide) (Sigma) was prepared to a stock solution of $10 \mathrm{mM}$ in absolute ethanol (vehicle). Cells were treated at indicated concentrations $(10-25 \mu \mathrm{M})$ as determined in the previous study (23). COX-2 coding sequence was a kind gift from the Prescott laboratory (University of Utah, USA) and pIRESneo3 vector was purchased from Clontech. COX-2 siRNA and control siRNA sequences were purchased from Applied Biosystems/Ambion. L-GSH was purchased from Sigma and a stock concentration of $500 \mathrm{mM}$ was prepared in $\mathrm{H}_{2} \mathrm{O}$. Hydrogen peroxide $\left(\mathrm{H}_{2} \mathrm{O}_{2}\right)$ was purchased from $\mathrm{BDH}$, AM251 and AM630 were both from Tocris. TRAIL was a kind gift from Dr Marion Macfarlane (MRC Toxicology Unit, University of Leicester).

Transient transfection. Over-expression of COX-2 in SW480 and HCT116 $\mathrm{Bax}^{-/}$: SW480 and HCT116 $\mathrm{Bax}^{-\nu^{-}}$cells were transiently transfected with $2.5 \mu \mathrm{g}$ COX-2 pIRESneo3 expression construct or pIRESneo3 vector alone using Lipofectamine 2000 (Invitrogen) following the manufacturer's protocol.

Inhibition of COX-2 expression in HCA7: COX-2 siRNA sequences were obtained from Applied Biosystems/Ambion (Warrington, UK). The following sequences were used: sequence no. 1 CCGAG GUGUAUGUAUGAGUtt and sequence no. 2 GCACUUCA CGCAUCAGUUUtt. The negative control siRNA (Ambion) had no homology to any sequence in the human or mouse genome. siRNA experiments were carried out as described previously (32).

Treatment of colorectal carcinoma cell lines. For all treatment conditions 2\% FBS DMEM/F12 medium containing glutamine $(2 \mathrm{mM})$, penicillin $(100 \mathrm{U} / \mathrm{ml})$ and streptomycin $(100 \mu \mathrm{g} / \mathrm{ml})$ were used in place of their standard growth medium.

Following transfection with COX-2 pIRESneo3 (72 h later) or COX-2 siRNA ( $24 \mathrm{~h}$ later) cells were treated with appropriate concentrations of anandamide or vehicle control for $72 \mathrm{~h}$. For experiments using TRAIL in HCT116 cells, cells were treated for $16 \mathrm{~h}$ with $0.1 \mu \mathrm{g} / \mathrm{ml}$ TRAIL. At this point adherent cells (those remaining attached to the flask) were removed by trypsinisation and shed cells (those having detached from the adherent monolayer) were counted separately. Shed cells represent the cells that have undergone cell death and are shown as a percentage of the total cell yield as previously described (33). For all experiments, each treatment condition and control were conducted in triplicate and repeated at least three times unless otherwise stated.

Western immunoblotting. Western blotting was carried out as described previously (13). COX-2 protein was detected using a mouse monoclonal COX-2 antibody (Cayman Chemical) at 1:2000. PARP was detected using a mouse monoclonal antibody (Alexis Corporation) at 1:5000. $\alpha$-tubulin was detected using a mouse monoclonal (Sigma) at 1:10,000. Bak was detected using a mouse monoclonal (Santa Cruz) and Bax was detected using a rabbit polyclonal (Santa Cruz) at 1:5000, the horseradish peroxidase (HRP)-conjugated secondary antibody was goat anti-mouse at 1:1000 (Sigma), HRPconjugated anti-rabbit antibody (Sigma) or HRP-conjugated anti-goat antibody (Sigma). 

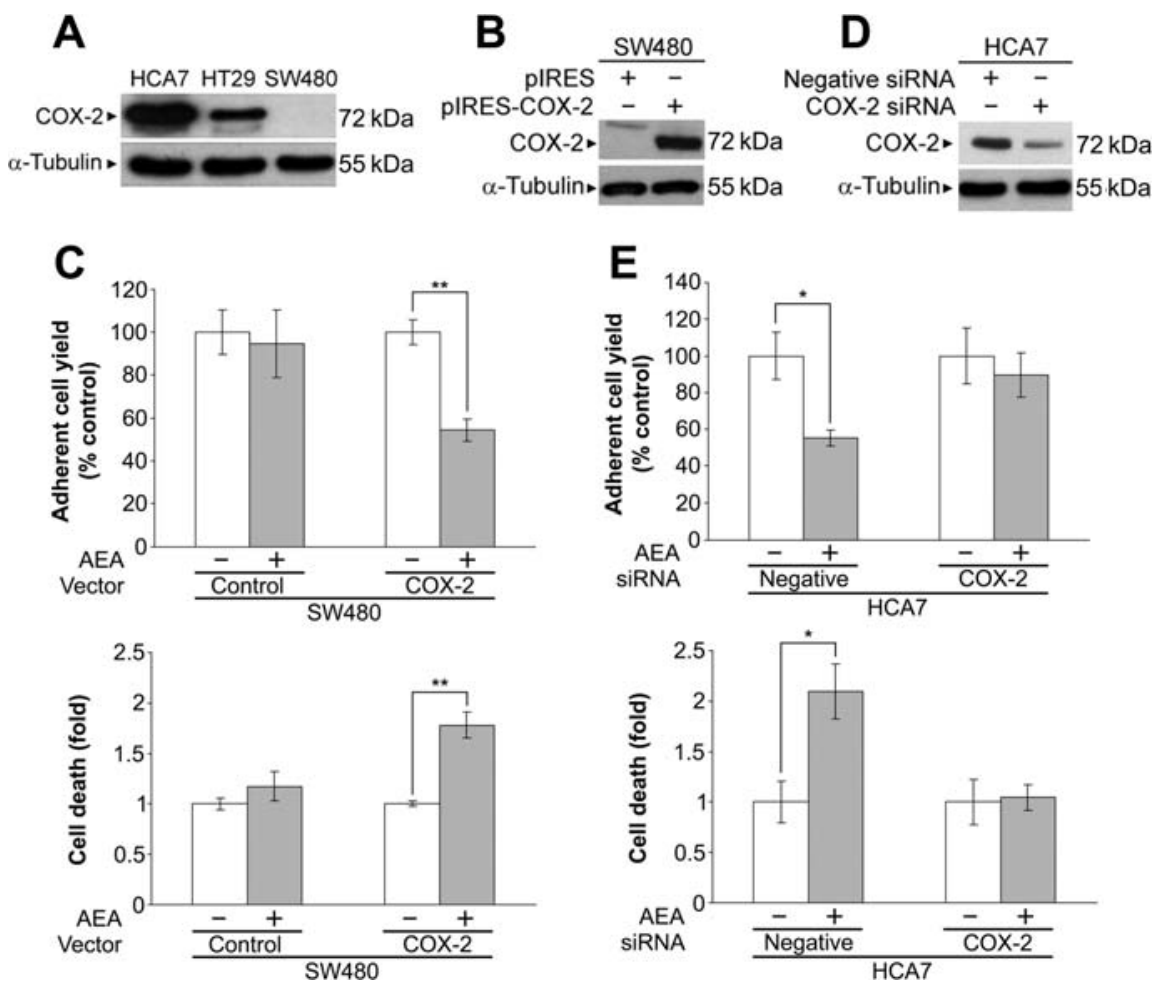

Figure 1. Anandamide-induced cell death is COX-2-dependent in colorectal cancer cells. (A) Level of basal COX-2 expression was confirmed in HCA7, HT29, and SW480 cells by Western blotting. COX-2 was detected in HT29 and HCA7, however SW480 expressed very low/undetectable levels of COX-2. Equal protein loading was confirmed using an antibody to $\alpha$-tubulin (B) COX-2 pIRESneo3 (COX-2) or pIRESneo3 were transiently transfected into the low COX-2 expressing cell line SW480; COX-2 expression is shown by Western blotting at time of treatment ( 0 h). Equal protein loading was confirmed using an antibody to $\alpha$-tubulin (C) transfected SW480 cells were treated with either vehicle control or $25 \mu \mathrm{M}$ anandamide (AEA) for $72 \mathrm{~h}$, adherent cells were counted and represented as a percentage of respective vehicle control and those cells that had detached from the adherent monolayer and shed into the medium were calculated as a percentage of the total cell population (attached plus floating cells). The shed cells were confirmed as non-apoptotic as previously described (23; data not shown) and are represented as a fold induction of cell death of respective vehicle controls. Results shown are means of triplicate results from three independent experiments \pm SEM. (D) COX-2 was knocked down by siRNA in the high COX-2 expressing cell line HCA7; COX-2 expression is shown by Western blotting at time of treatment $(0 \mathrm{~h})$. Equal protein loading was confirmed using an antibody to $\alpha$-tubulin (E) HCA7 cells were transfected with $20 \mathrm{nM}$ negative control siRNA or an siRNA sequence targeted against COX-2. Seventy-two hours after transfection the cells were treated with $25 \mu \mathrm{M}$ anandamide (AEA) for $72 \mathrm{~h}$. Data points shown are means of at least three independent experiments conducted in triplicate $\pm \mathrm{SEM}\left({ }^{*} \mathrm{p}<0.05,{ }^{* *} \mathrm{p}<0.01\right)$.

Statistical analyses. Statistical analyses were performed using Student's t-test and Dunnett's t-test and expressed as: ${ }^{*} \mathrm{p}<0.05,{ }^{* *} \mathrm{p}<0.01,{ }^{* * *} \mathrm{p}<0.001$.

\section{Results}

Increased expression of COX-2 sensitises the SW480 colorectal cancer cell line to anandamide-induced cell death. Previously we established that pharmacological inhibition of COX-2 activity confers resistance to anandamide-induced cell death (23), suggesting that high COX-2 expression in tumour cells could be used to target colorectal cancer cells for anandamide-induced cell death. However, as there was no direct genetic evidence, initial experiments were carried out to confirm that COX-2 expression regulates the sensitivity of colorectal epithelial cells to anandamide-induced cell death. A colorectal cell line that has undetectable COX-2 expression, SW480 (Fig. 1A), was transiently transfected with COX-2 and protein expression confirmed by Western blotting (Fig. 1B). Interestingly, whilst the vector controls SW480 cells were intrinsically resistant to anandamide-induced cell death (Fig. 1C), transient over-expression of COX-2 resulted in the significant sensitisation of SW480 cells to anandamideinduced cell death (Fig. 1C). Cell death was confirmed as the non-apoptotic cell death previously described in detail (23; data not shown).

Reduction of COX-2 expression by RNAi inhibits anandamideinduced cell death in HCA7 colorectal cancer cells. In determining the role of COX-2 expression in anandamide-induced cell death, it was also important to determine whether a reduction in COX-2 protein expression conferred resistance to anandamide treatment in a previously sensitive cell line. Therefore HCA7 cells, which express very high levels of COX-2 (Fig. 1A) and have previously been reported to be sensitive to anandamide-induced cell death (23), were transfected with a COX-2 siRNA. The reduction in COX-2 protein expression was confirmed by Western blotting (Fig. 1D). Results (Fig. 1E) show that the reduction of COX-2 expression in the HCA7 cell line significantly protected the cells from growth inhibition and anandamide-induced cell death.

Anandamide induces cell death in apoptosis-resistant colorectal cancer cells. As colorectal cancer cells can acquire mutations that disrupt the programmed cell death pathways required by many chemotherapeutics for efficacy, there is an urgent need to find novel agents that can target the cancer cells and are not reliant on an intact intrinsic apoptotic path- 

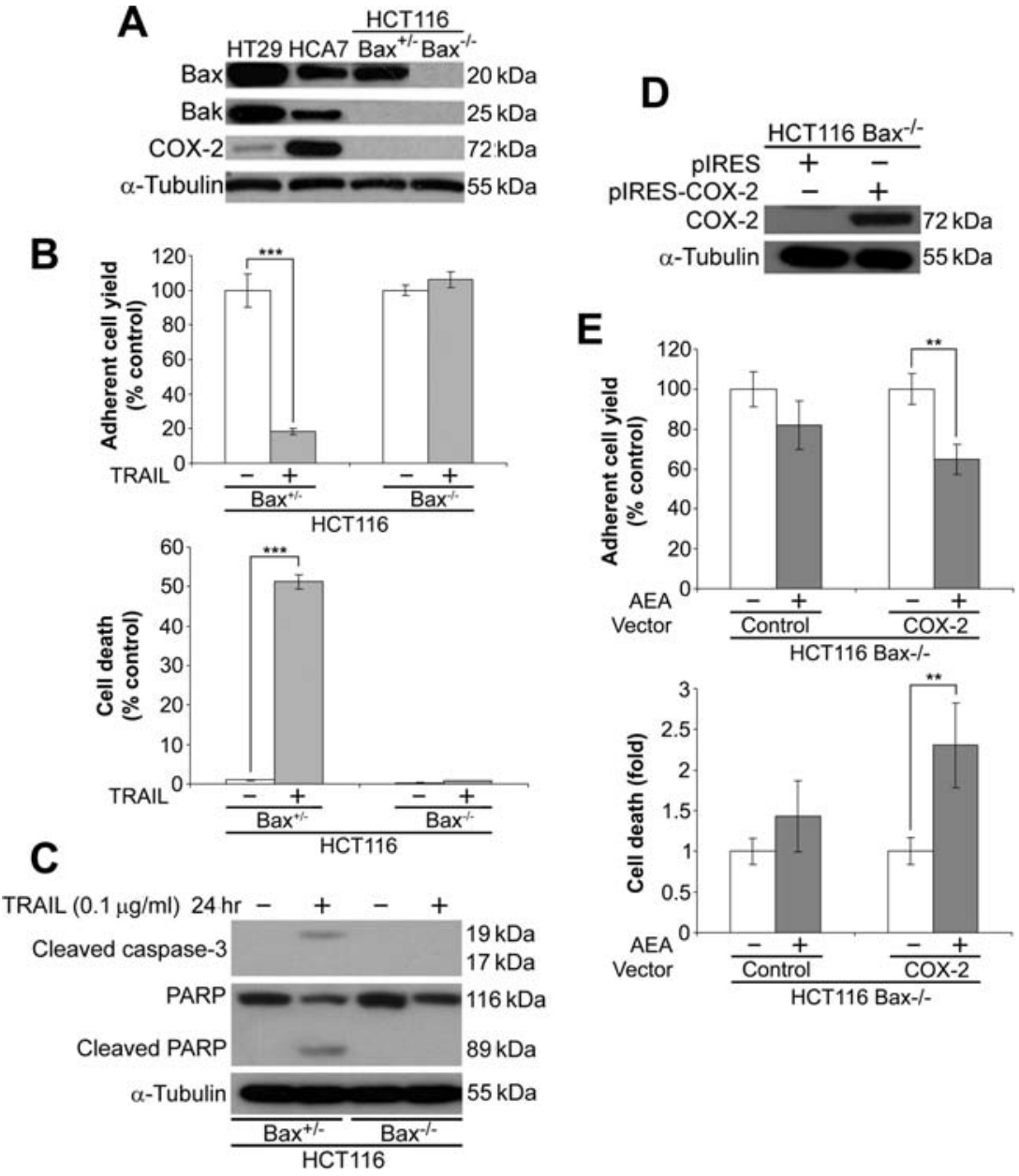

Figure 2. Anandamide induces COX-2-dependent cell death in the HCT116 Bax ${ }^{-/}$apoptosis-resistant cell line. (A) Cell lysates were collected from control cell cultures of HT29, HCA7, HCT116 Bax ${ }^{+/}$and HCT116 $\mathrm{Bax}^{-/}$and subjected to Western blotting. Cell lysates were loaded by equal protein concentration and expression of Bax, Bak and COX-2 determined. HCA7 is used as a positive control for COX-2 protein expression and equal protein loading was confirmed using an antibody to $\alpha$-tubulin. (B) HCT116 Bax ${ }^{+/}$and HCT116 Bax $/$were treated with $0.1 \mu \mathrm{g} / \mathrm{ml}$ TRAIL for $16 \mathrm{~h}$. Adherent cells were counted and represented as a percentage of respective vehicle control and those cells that had detached from the adherent monolayer and shed into the medium were calculated as a percentage of the total cell population (shed cells). The shed cells were then represented as a fold induction of cell death of respective vehicle controls. Results shown are means of triplicate results \pm SEM and are representative of three separate experiments. (C) To confirm TRAIL-induced apoptosis, shed cells were collected and cell lysates were subjected to Western blot analysis for PARP and cleaved caspase 3. Equal loading was confirmed using an anti- $\alpha$-tubulin antibody. (D) HCT116 Bax ${ }^{-/}$, low expressors of COX-2, were transfected with COX-2 pIRESneo3 (COX-2) and pIRESneo3 (vector) and COX-2 expression confirmed by Western blotting at the time of treatment. (E) The HCT116 COX-2 pIRESneo3 and pIRESneo3 (vector) were treated with $25 \mu \mathrm{M}$ anandamide (AEA) or vehicle control (control) for $72 \mathrm{~h}$. Adherent cells were counted and represented as a percentage of respective vehicle control and those cells that had detached from the adherent monolayer and shed into the medium were calculated as a percentage of the total cell population (shed cells) as previously described. The shed cells were confirmed as non-apoptotic as previously described (23; data not shown) and are represented as a fold induction of cell death of respective vehicle controls. Results shown are means of four independent experiments carried out in triplicate $\pm \mathrm{SEM}\left({ }^{*} \mathrm{p}<0.05,{ }^{* *} \mathrm{p}<0.01\right.$, $\left.{ }^{* * *} \mathrm{p}<0.001\right)$.

way to induce cell death. We would suggest that anandamide may represent such an agent, inducing non-apoptotic cell death in colorectal tumour cells which express COX-2.

To test the hypothesis, we utilised the HCT116 $\mathrm{Bax}^{-/}$ colorectal carcinoma cell line (Fig. 2A). The HCT116 cells from which these cells are isolated were also deficient in Bak expression (Fig. 2A). As Bak and Bax are both critical mediators of apoptosis (34), the deficiency of both in the HCT116 $\mathrm{Bax}^{-/-}$cells renders them resistant to the induction of apoptosis. HCT116 $\mathrm{Bax}^{-/-}$cells have previously been shown to be significantly protected against fluorouracil (5-FU) and completely resistant to indomethacin and sulindac treatment (31). To further establish that the HCT116 $\mathrm{Bax}^{-/}$cells were resistant to apoptosis, cells were treated with TRAIL, a potent inducer of apoptosis (35); the results are presented in
Fig. 2. Heterozygote $\mathrm{Bax}^{+/-}$cells were found to be highly sensitive to TRAIL resulting in a decrease in adherent cell yield and induction of apoptosis (Fig. 2B). Apoptosis was confirmed in these $\mathrm{Bax}^{+/-}$cells by detection of both cleaved caspase 3 and cleaved PARP (Fig. 2C). In contrast TRAIL did not affect adherent cell yield or induce cell death in $\mathrm{Bax}^{-/-}$ cells, demonstrating that these cells are resistant to the induction of apoptosis (Fig. 2B).

Having confirmed that the HCT116 $\mathrm{Bax}^{-/}$are resistant to apoptosis, we sought to determine whether anandamide could induce COX-2-dependent cell death in this cell line. HCT116 $\mathrm{Bax}^{-/-}$cells (which have low/undetectable endogenous levels of COX-2) were transiently transfected with COX-2 (Fig. 2D), and sensitivity to anandamide-induced cell death compared with the HCT116 $\mathrm{Bax}^{-/-}$vector control cells 


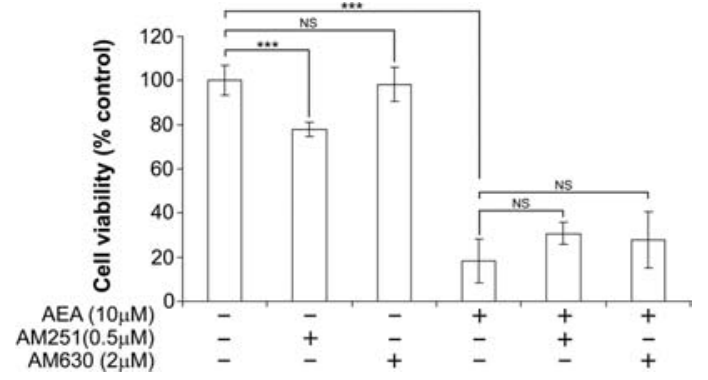

Figure 3. Response of HCA7 cells to anandamide is not mediated via cannabinoid receptor activation. HCA7 cells were pre-treated for $2 \mathrm{~h}$ with concentrations of receptor antagonist previously shown to block receptormediated signalling in CRC cells (13); either the CB1 receptor antagonist (AM251 $0.5 \mu \mathrm{M}$ ) the CB2 receptor antagonist (AM630 $2 \mu \mathrm{M}$ ) or vehicle control before addition of $10 \mu \mathrm{M}$ anandamide (AEA) or appropriate vehicle control. After $72 \mathrm{~h}$ cell viability was assessed by MTT assay. Neither cannabinoid receptor antagonists (CB1 or CB2) significantly protected HCA7 cells from the decrease in cell survival induced by anandamide. Results shown are represented as a percentage survival of vehicle control Data points are means from three separate experiments each conducted in sextuplet \pm SEM $\left({ }^{*} \mathrm{p}<0.05,{ }^{* *} \mathrm{p}<0.01,{ }^{* * *} \mathrm{p}<0.001\right)$.
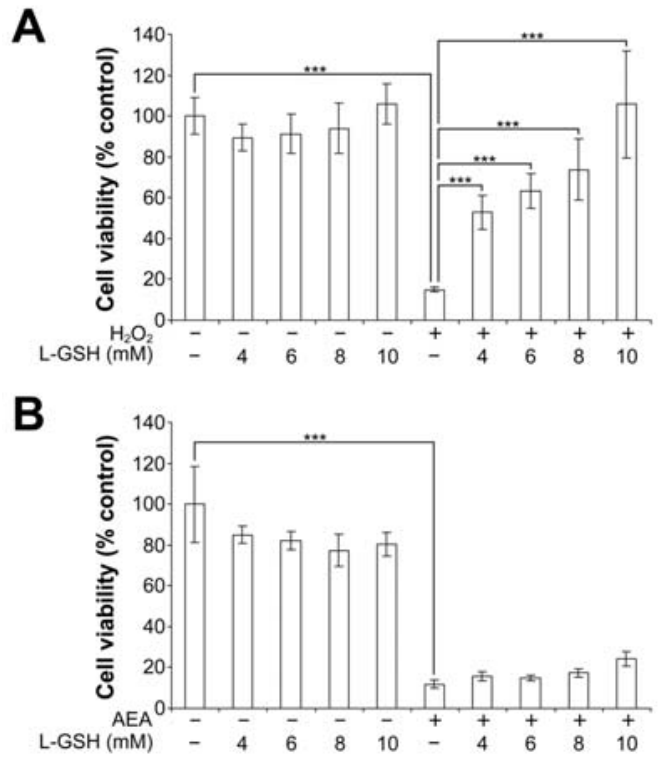

Figure 4. Response of HCA7 cells to anandamide is not mediated via ROS generation. (A) The anandamide responsive high COX-2 expressing cell line (HCA7) cells were pre-treated with increasing concentrations of L-GSH (4, 6,8 , or $10 \mathrm{mM}$ ) for $4 \mathrm{~h}$ prior to treatment with $1 \mathrm{mM} \mathrm{H}_{2} \mathrm{O}_{2}$ for $24 \mathrm{~h}$. After $24 \mathrm{~h}$ cell survival was assessed by MTT assay. L-GSH dose-dependently protected $\mathrm{HCA} 7$ cells from $\mathrm{H}_{2} \mathrm{O}_{2}$ reduction in cell survival, therefore protecting against the ROS species damage by $\mathrm{H}_{2} \mathrm{O}_{2}$. (B) HCA7 cells were pre-treated with increasing concentrations of the ROS scavenger, L-glutathione (L-GSH) $(4,6,8$, or $10 \mathrm{mM})$ for $4 \mathrm{~h}$ prior to addition of $25 \mu \mathrm{M}$ anandamide (AEA) or appropriate vehicle control. After $72 \mathrm{~h}$ cell survival was assessed by MTT assay. L-GSH was not able to rescue HCA7 cells from the reduction in cell survival induced by anandamide. Results shown are represented as a percentage survival of vehicle control. Data points are means of experiments conducted in sextuplet \pm SEM and are representative of 3 independent experiments $\left({ }^{*} \mathrm{p}<0.05,{ }^{* *} \mathrm{p}<0.01,{ }^{* * *} \mathrm{p}<0.001\right)$.

(Fig. 2E). Importantly, the HCT116 $\mathrm{Bax}^{-/-}$vector control cells were not significantly sensitive to anandamide-induced growth inhibition [pIRESneo3 (vector) control cells], again emphasising that anandamide treatment is not generally toxic to colorectal epithelial cells. However, when transfected with COX-2, anandamide treatment resulted in a significant decrease in cell yield and induction of cell death in the HCT116 Bax ${ }^{-/}$cells (Fig. 2E). Cell death was atypical, showing characteristics of the non-apoptotic death described previously in detail (data not shown, 23). For the first time, these results demonstrate that when COX-2 is highly expressed, anandamide can induce cell death in apoptotic resistant colorectal carcinoma cells.

Anandamide-induced cell death is not mediated through cannabinoid receptors. Although we have previously shown that anandamide-induced cell death in colorectal cancer cell lines is non-apoptotic (23), it has not been established whether this cell death is mediated via the CB receptors. As noted above, cannabinoids have the ability to activate cannabinoid receptors, $\mathrm{CB} 1$ and/or CB2, although they can also act independently of cannabinoid receptors $(22,25)$. We have previously shown that the COX-2 expressing cell line HCA7 expresses both $\mathrm{CB} 1$ and $\mathrm{CB} 2$ receptors (13). In order to determine whether anandamide's effect on cell viability is mediated by the cannabinoid receptors $\mathrm{CB} 1$ and $\mathrm{CB} 2$, we used cannabinoid receptor antagonists AM251 and AM630, respectively. AM251 and AM630 were used at concentrations previously published (13,36; 0.5 and $2 \mu \mathrm{M}$, respectively). AM630 alone did not affect cell viability; however at all concentrations tested $(0.2-2 \mu \mathrm{M})$ AM251 treatment did cause a small but significant reduction in cell viability (consistent with previous findings) (13). However, despite this effect on cell yield, neither AM251 nor AM630 significantly repressed the effects of anandamide on HCA7 cells (Fig. 3). This is in contrast to previous reports showing CB1dependent anandamide-induced cell death in colorectal cells (17). Data presented here show that reduction in cell viability in colorectal epithelial cells does not require cannabinoid receptor activation, suggesting that therapeutic efficacy of anandamide would not be limited by cannabinoid receptor expression on target tumour cells.

Anandamide-induced non-apoptotic cell death is not mediated through ROS production. Interestingly, the observation that anandamide induces a $C B$ receptor-independent non-apoptotic cell death in colorectal cells (23) was supported by a study which reported that anandamide induced cell death in primary hepatic stellate cells (HSC) (24). However, the CB receptorindependent necrotic death reported by Siegmund and colleagues was associated with an increase in ROS formation, meaning that the HSCs could be rescued from cell death by glutathione (24). Therefore, to investigate whether the cell death induced by anandamide was mediated by ROS in the colorectal epithelial cells, we sought to determine whether exogenous glutathione (L-GSH) could protect colorectal cells from cell death. For this we used the anandamide-sensitive colorectal cancer cell line HCA7. As a positive control for L-GSH activity, treatment with L-GSH showed a dosedependent inhibition of hydrogen peroxide $\left(\mathrm{H}_{2} \mathrm{O}_{2}\right)$-induced cell death in HCA7 cells (Fig. 4A). In comparison, even though anandamide significantly reduced HCA7 cell viability, L-GSH had little effect on anandamide-induced cell death (Fig. 4B). Since L-GSH did not prevent the reduction in cell 
survival induced by anandamide, these results suggest that anandamide-induced growth inhibition is not mediated via the production of ROS in colorectal cancer cells.

Taken together, these experiments show that anandamide can induce cell death in cells that have acquired resistance to apoptosis, and provide direct genetic evidence that this cell death is dependent on the expression of COX-2 in colorectal epithelial cells. In addition, this COX-2-dependent death was shown to be independent of cannabinoid receptor engagement (CB1 or CB2), and not a direct consequence of ROS formation.

\section{Discussion}

Advanced colorectal cancer remains difficult to treat; many patients presenting with metastatic disease are resistant to current therapies, explaining the high mortality associated with this cancer. Therefore there is an urgent need to improve therapeutic outcome for colorectal cancer through developing novel approaches to treat resistant disease. One of the key problems in treating cancer is primary or acquired resistance to chemotherapy-induced apoptosis due to an accumulation of mutations affecting genes such bax, often resulting in treatment failure (37). Hence it is not surprising that reagents that can induce alternate cell death pathways including autophagic cell death $(38,39)$ and paraptosis $(40,41)$ have begun to receive the attention of cancer biologists $(42,43)$. For the first time, the data presented here highlight the fact that anandamide, previously shown to induce a non-apoptotic form of cell death, can be used to suppress the growth and induce cell death of $\mathrm{bax}^{-/-}$apoptosis-resistant colorectal tumour cells. This has potentially important implications for the treatment of apoptosis-resistant tumours.

Previously we have reported that anandamide treatment induced a non-apoptotic cell death in colorectal epithelial cells, and using pharmacological inhibition, shown that COX-2 activity was important for the cytotoxic effects of anandamide (23). In the current study we have provided direct genetic evidence that establishes sensitivity to anandamide-induced cell death is dependent on COX-2 expression, a finding recently supported by a study in murine squamous carcinoma cells (44). The importance of COX-2 in the response to anandamide is emphasised by the fact that COX-2 is over-expressed in the majority of colorectal carcinomas $(85 \%)$, and in a large population of colorectal adenomas (40-50\%) (29), suggesting that anandamide treatment may be of benefit both in chemoprevention as well as treatment of advanced disease.

In some previous studies, anandamide has been shown to exert its actions through $\mathrm{CB}$ receptors; the action of endocannabinoids via $\mathrm{CB}$ receptors has been reported in a number of tumour cell types $(21,45,46)$. Therefore, it was important to establish whether the anti-neoplastic effect of anandamide could be attributed to $\mathrm{CB}$ receptor activation in the colorectal epithelial cells. However, neither CB1 nor CB2 receptor antagonists could abrogate the reduction in cell viability induced by anandamide, demonstrating that the response to anandamide in colorectal cells is independent of $\mathrm{CB}$ receptor activation. This is consistent with other studies demonstrating that endocannabinoids can act independently of $\mathrm{CB}$ receptor activation $(22,24,47)$ and suggests that any possible clinical application would not be limited by $\mathrm{CB}$ receptor expression.

Interestingly, unlike the findings of Siegmund and colleagues in hepatic stellate cells (24), ROS were not the main mediators of death in colorectal epithelial cells since L-GSH only conferred limited protection (6-12\%) against the cell death-inducing effects of anandamide. This finding is of importance as L-GSH is expressed in the liver, and if anandamide were inhibited by L-GSH it would potentially limit the therapeutic potential of this reagent at a common site for metastatic disease in colorectal cancer patients. However as the majority of cell death occurs in the presence of pharmacologically relevant levels of L-GSH, anandamide has the potential to be effective in patients with advanced disease.

In conclusion, as anandamide induced cell death in the HCT116 $\mathrm{Bax}^{-\nu_{-}}$cells, this report has demonstrated for the first time that anandamide can efficiently remove cells that are resistant to the induction of apoptosis. In this study we uncover a novel utilisation for aberrant COX-2 expression in tumour cells that are resistant to apoptosis, targeting the enzymic activity to promote the death of the resistant cells. It is also important to highlight that during the progression from primary tumour to the development of metastatic disease many gene mutations occur resulting in metastases being more likely to be resistant to apoptosis (48). Interestingly, colorectal cancer metastases have been shown to over-express COX-2 compared with normal epithelium (49). Anandamide may therefore be an effective anti-metastatic agent, able to reduce the growth and induce cell death of apoptotic defective cells that express $\mathrm{COX}-2$, whilst sparing those cells that do not express COX-2. Furthermore, as COX-2 is also over-expressed in a number of other tumour types including prostate, breast and oral cancer this work has a wider implications, suggesting that the anti-cancer effects of anandamide may not be limited to colorectal cancer.

\section{Acknowledgements}

Many thanks to Maryam H. Zadeh for making the COX-2 expression construct. This work was supported by a Cancer Research UK programme grant, the Citrina Foundation and the John James Bristol Foundation.

\section{References}

1. Hanahan D and Weinberg RA: The hallmarks of cancer. Cell 100: 57-70, 2000

2. Roth W and Reed JC: Apoptosis and cancer: when BAX is TRAILing away. Nat Med 8: 216-218, 2002.

3. Sinicrope FA and Penington RC: Sulindac sulfide-induced apoptosis is enhanced by a small-molecule Bcl-2 inhibitor and by TRAIL in human colon cancer cells overexpressing Bcl-2. Mol Cancer Ther 4: 1475-1483, 2005.

4. Violette S, Poulain L, Dussaulx E, et al: Resistance of colon cancer cells to long-term 5-fluorouracil exposure is correlated to the relative level of $\mathrm{Bcl}-2$ and $\mathrm{Bcl}-\mathrm{X}(\mathrm{L})$ in addition to $\mathrm{Bax}$ and p53 status. Int J Cancer 98: 498-504, 2002.

5. Guzman M: Cannabinoids: potential anticancer agents. Nat Rev Cancer 3: 745-55, 2003.

6. Bifulco M, Laezza C, Pisanti S and Gazzerro P: Cannabinoids and cancer: pros and cons of an antitumour strategy. Br J Pharmacol 148: 123-135, 2006.

7. Sarfaraz S, Adhami VM, Syed DN, Afaq F and Mukhtar H: Cannabinoids for cancer treatment: progress and promise. Cancer Res 68: 339-342, 2008. 
8. Matsuda LA, Lolait SJ, Brownstein MJ, Young AC and Bonner TI: Structure of a cannabinoid receptor and functional expression of the cloned cDNA. Nature 346: 561-564, 1990

9. Munro S, Thomas KL and Abu-Shaar M: Molecular characterization of a peripheral receptor for cannabinoids. Nature 365 : 61-65, 1993

10. Howlett AC, Qualy JM and Khachatrian LL: Involvement of Gi in the inhibition of adenylate cyclase by cannabimimetic drugs. Mol Pharmacol 29: 307-313, 1986.

11. Davis MI, Ronesi J and Lovinger DM: A predominant role for inhibition of the adenylate cyclase/protein kinase A pathway in ERK activation by cannabinoid receptor 1 in N1E-115 neuroblastoma cells. J Biol Chem 278: 48973-48980, 2003.

12. Blazquez C, Gonzalez-Feria L, Alvarez L, Haro A, Casanova ML and Guzman M: Cannabinoids inhibit the vascular endothelial growth factor pathway in gliomas. Cancer Res 64: 5617-5623, 2004.

13. Greenhough A, Patsos HA, Williams AC and Paraskeva C: The cannabinoid delta(9)-tetrahydrocannabinol inhibits RAS-MAPK and PI3K-AKT survival signalling and induces BAD-mediated apoptosis in colorectal cancer cells. Int J Cancer 121: 2172-2180, 2007.

14. Wang D, Wang H, Ning W, Backlund MG, Dey SK and DuBois RN: Loss of cannabinoid receptor 1 accelerates intestinal tumor growth. Cancer Res 68: 6468-6476, 2008.

15. Devane WA, Hanus L, Breuer A, et al: Isolation and structure of a brain constituent that binds to the cannabinoid receptor. Science 258: 1946-1949, 1992.

16. Di Marzo V, Bifulco M and De Petrocellis L: The endocannabinoid system and its therapeutic exploitation. Nat Rev Drug Discov 3: 771-784, 2004.

17. Ligresti A, Bisogno T, Matias I, et al: Possible endocannabinoid control of colorectal cancer growth. Gastroenterology 125 : 677-687, 2003.

18. Laezza C, Pisanti S, Crescenzi E and Bifulco M: Anandamide inhibits $\mathrm{Cdk} 2$ and activates Chk1 leading to cell cycle arrest in human breast cancer cells. FEBS Lett 580: 6076-6082, 2006.

19. Joseph J, Niggemann B, Zaenker KS and Entschladen F: Anandamide is an endogenous inhibitor for the migration of tumor cells and $\mathrm{T}$ lymphocytes. Cancer Immunol Immunother 53: 723-728, 2004

20. Ramer R and Hinz B: Inhibition of cancer cell invasion by cannabinoids via increased expression of tissue inhibitor of matrix metalloproteinases-1. J Natl Cancer Inst 100: 59-69, 2008.

21. Grimaldi C, Pisanti S, Laezza C, et al: Anandamide inhibits adhesion and migration of breast cancer cells. Exp Cell Res 312: 363-373, 2006

22. Maccarrone M, Lorenzon T, Bari M, Melino G and FinazziAgro A: Anandamide induces apoptosis in human cells via vanilloid receptors. Evidence for a protective role of cannabinoid receptors. J Biol Chem 275: 31938-31945, 2000

23. Patsos HA, Hicks DJ, Dobson RR, et al: The endogenous cannabinoid, anandamide, induces cell death in colorectal carcinoma cells: a possible role for cyclooxygenase 2. Gut 54: 1741-1750, 2005.

24. Siegmund SV, Uchinami H, Osawa Y, Brenner DA and Schwabe RF: Anandamide induces necrosis in primary hepatic stellate cells. Hepatology 41: 1085-1095, 2005.

25. Contassot E, Wilmotte R, Tenan M, et al: Arachidonylethanolamide induces apoptosis of human glioma cells through vanilloid receptor-1. J Neuropathol Exp Neurol 63: 956-963, 2004.

26. Izzo AA, Aviello G, Petrosino S, et al: Increased endocannabinoid levels reduce the development of precancerous lesions in the mouse colon. J Mol Med 86: 89-98, 2008.

27. Ueda N: Endocannabinoid hydrolases. Prostaglandins Other Lipid Mediat 68-69: 521-534, 2002.

28. Kozak KR, Crews BC, Morrow JD, et al: Metabolism of the endocannabinoids, 2-arachidonylglycerol and anandamide, into prostaglandin, thromboxane, and prostacyclin glycerol esters and ethanolamides. J Biol Chem 277: 44877-44885, 2002.
29. Elder DJ, Baker JA, Banu NA, Moorghen M and Paraskeva C: Human colorectal adenomas demonstrate a size-dependent increase in epithelial cyclooxygenase- 2 expression. J Pathol 198: 428-434, 2002.

30. LeBlanc H, Lawrence D, Varfolomeev E, et al: Tumor-cell resistance to death receptor-induced apoptosis through mutational inactivation of the proapoptotic Bcl-2 homolog Bax. Nat Med 8: 274-281, 2002

31. Zhang L, Yu J, Park BH, Kinzler KW and Vogelstein B: Role of $\mathrm{BAX}$ in the apoptotic response to anticancer agents. Science 290: 989-992, 2000.

32. Kaidi A, Williams AC and Paraskeva C: Interaction between beta-catenin and HIF-1 promotes cellular adaptation to hypoxia. Nat Cell Biol 9: 210-217, 2007

33. Diaz GD, Paraskeva C, Thomas MG, Binderup L and Hague A: Apoptosis is induced by the active metabolite of vitamin D3 and its analogue EB1089 in colorectal adenoma and carcinoma cells: possible implications for prevention and therapy. Cancer Res 60: 2304-2312, 2000.

34. Wei MC, Zong WX, Cheng EH, et al: Proapoptotic BAX and $\mathrm{BAK}$ : a requisite gateway to mitochondrial dysfunction and death. Science 292: 727-730, 2001

35. Wang S and El-Deiry WS: TRAIL and apoptosis induction by TNF-family death receptors. Oncogene 22: 8628-8633, 2003

36. Ibrahim MM, Porreca F, Lai J, et al: CB2 cannabinoid receptor activation produces antinociception by stimulating peripheral release of endogenous opioids. Proc Natl Acad Sci USA 102: 3093-3098, 2005

37. Brown JM and Wilson G: Apoptosis genes and resistance to cancer therapy: what does the experimental and clinical data tell us? Cancer Biol Ther 2: 477-490, 2003.

38. Klionsky DJ: Autophagy: from phenomenology to molecular understanding in less than a decade. Nat Rev Mol Cell Biol 8: 931-937, 2007

39. Kroemer $\mathrm{G}$ and Levine B: Autophagic cell death: the story of a misnomer. Nat Rev Mol Cell Biol 9: 1004-1010, 2008.

40. Sperandio S, de Belle I and Bredesen DE: An alternative, nonapoptotic form of programmed cell death. Proc Natl Acad Sci USA 97: 14376-14381, 2000.

41. Wang Y, Li X, Wang L, et al: An alternative form of paraptosislike cell death, triggered by TAJ/TROY and enhanced by PDCD5 overexpression. J Cell Sci 117: 1525-1532, 2004.

42. Kroemer G, Galluzzi L, Vandenabeele P, et al: Classification of cell death: recommendations of the Nomenclature Committee on Cell Death 2009. Cell Death Differ 16: 3-11, 2009.

43. Galluzzi L, Maiuri MC, Vitale I, et al: Cell death modalities: classification and pathophysiological implications. Cell Death Differ 14: 1237-1243, 2007.

44. Van Dross RT: Metabolism of anandamide by COX-2 is necessary for endocannabinoid induced cell death in tumorigenic keratinocytes. Mol Carcinogenesis 48: 724-732, 2009.

45. De Petrocellis L, Melck D, Palmisano A, et al: The endogenous cannabinoid anandamide inhibits human breast cancer cell proliferation. Proc Natl Acad Sci USA 95: 8375-8380, 1998.

46. Bifulco M, Laezza C, Portella G, et al: Control by the endogenous cannabinoid system of ras oncogene-dependent tumor growth. FASEB J 15: 2745-2747, 2001.

47. Ramer R, Brune K, Pahl A and Hinz B: R(+)-methanandamide induces cyclooxygenase-2 expression in human neuroglioma cells via a non-cannabinoid receptor-mediated mechanism. Biochem Biophys Res Commun 286: 1144-1152, 2001.

48. Oliver L, Cordel S, Barbieux I, et al: Resistance to apoptosis is increased during metastatic dissemination of colon cancer. Clin Exp Metastasis 19: 175-180, 2002.

49. Chen WS, Wei SJ, Liu JM, Hsiao M, Kou-Lin J and Yang WK: Tumor invasiveness and liver metastasis of colon cancer cells correlated with cyclooxygenase-2 (COX-2) expression and inhibited by a COX-2-selective inhibitor, etodolac. Int J Cancer 91: 894-899, 2001 